\title{
Penerapan IPTEKS pada usaha handycraft ketak berorientasi ekspor di desa Karang Bayan Kecamatan Lingsar Kabupaten Lombok Barat
}

\author{
A.A.A. Triadi ${ }^{\star 1}$, M. Nuarsa ${ }^{1}$, DG. Bisma ${ }^{2}$ \\ ${ }^{1}$ Teknik Mesin Fakultas Teknik Universitas Mataram, Jln. Majapahit No. 62 Mataram Nusa Tenggara \\ Barat Kode Pos: 83125, Telp. (0370) 636087; 636126; ext 128 Fax (0370) 636087. \\ 2 Manajemen Fakultas Ekonomi Universitas Mataram, Jln. Majapahit No. 62 Mataram Nusa Tenggara \\ Barat Kode Pos : 83125, Telp. (0370) 636087; 636126; ext 128 Fax (0370) 636087. \\ *Email: alittriadi@yahoo.co.id
}

\section{ARTICLE INFO}

Article History:

Received February 2017

Accepted October 2017

Available online 30 December 2017

Keywords:

Woven ketak

Design

Dryer

Business management

In cooperation with SNMI XI 2017

Special Edition

\section{ABSTRACT}

Products Woven or ketak is a handicraft product produced by the 'artisans' community in the village of Karang Bayan West Lombok with raw materials from plants ketak. In the process it takes the necessary skills to weave and combine woven ketak with other natural products such as wood, pottery, coconut shell or bone. The marketing of wicker web products has penetrated the export market, especially the Japanese market. Problems experienced by industrial partners or the artisan's community is the transfer of design from businessmen to crafters (door to door), drying process during the rainy season and business management. Designs are sometimes made by the buyer and sent to the entrepreneur via email. The solving problem that is faced by the producents is the important thing to be done, by approaching the centralized design transfer training (in one place that is done in the partner house). The next one, making a mechanical dryer with two heat sources located beside left and lower right and LPG-fueled (clean, practical, economical and environmentally friendly). Next step, by providing business management assistance (finance and marketing).

\section{PENDAHULUAN}

Ketak adalah sejenis tanaman merambat yang biasanya tumbuh di semak-semak, hutan, kebun dan lain-lain. Kerajinan ketak adalah jenis kerajinan rakyat di Propinsi Nusa Tenggara Barat (NTB) khususnya daerah Lombok. Kerajinan ketak merupakan kerajinan souvenir atau sejenis aksesories interior, ekterior hotel bungalow, kantor, rumah dan lain-lain (Dinas Perindustrian dan
Perdagangan Propinsi Nusa Tenggara Barat, 2014). Kerajinan ketak terbuat dari ketak yang dianyam sesuai dengan disain pemesan seperti : piring ketak, kecupu, tempat buah, tas, tas gantung, kaling, kotak, toples, tempat botol, tatakan gelas, basi dan banyak lagi produk kerajinan ketak.

Salah satu permasalahan di industri kecil/pengrajin ketak adalah masalah pengeringan 
produk dan kurangnya variasi warna pada berbagai ragam produk. Masalah pengeringan menjadi hal yang sangat vital bila tiba musim hujan. Di satu sisi datangnya order tidak mengenal musim. Pengeringan yang selama ini dilakukan oleh pengerajin adalah dengan menjemur di terik sinar matahari.Bila warna anyaman ketak masih hijau maka diperlukan waktu pengeringan sampai 4 hari. Itu bisa tercapai bila cuaca setiap hari cerah. Bila cuaca tidak menentu maka diperlukan waktu pengeringan yang lebih panjang. Kondisi ini akan berpengaruh pada pesanan (order).

Bila pengeringan anyaman ketak dilakukan dengan metode pengasapan secara langsung yang dihasilkan oleh pembakaran serbuk kayu, kayu bakar maupun biomass jenis yang lain akan yang tidak seragam dan kehitam-hitaman, hal ini juga terjadi pada kayu (Agustina dkk, 2003, Efrida, 1999). Sedangkan warna akhir yang diinginkan adalah warna coklat kekuning-kuningan. Proses menjaga kestabilan temperature pengeringan (50 $-60{ }^{\circ} \mathrm{C}$ ) dengan alat ini sulit dilakukan dan tidak dapat difungsikan dalam waktu 24 jam.

Kendala lain yang dialami adalah transfer desain dari penerima order (Nusa Indah Workshop dan Vanani Workshop) ke para perajin yang tersebar di lingkungan desa Karang Bayan. Selama ini transfer desain dilakukan secara door to door, sehingga dibutuhkan waktu yang lebih lama dan menjadi kekhawatiran produk order tidak bisa diselesaikan tepat waktu.

Dari diskusi dengan mitra terlihat bahwa manajemen administrasi dan keuangan yang selama ini dilaksanakan belum sesuai dengan standar yang ada, sehingga menjadi masalah bila order datang bersamaan. Mitra mengalami kesulitan untuk menangani hal tersebut.

\section{METODE PENELITIAN}

Adapun pendekatan yang dilakukan untuk memecahkan permasalahan yang ada pada pengusaha kerajinan anyaman ketak meliputi:

\section{Analisa kebutuhan}

Pengumpulan informasi dilakukan dengan cara observasi, wawancara dan mengikuti kegiatan yang diikuti oleh perajin. Pengumpulan data antara lain meliputi problem utama yang dihadapi. Kegiatan rutin dan insidentil yang dilakukan, keorganisasian, keadaan masyarakat baik dilihat dari segi sosial ekonomi, pendidikan maupun pandangannya terhadap suatu inovasi baru dan lain-lain.

\section{Analisa daya serap materi pelatihan dan pendampingan manajemen}

Pengumpulan data dilakukan bersamaan dengan tahap kegiatan 1, meliputi masalah daya serap pengrajin sehubungan dengan penerapan proses transfer desain pembuatan produk dan manajemen usaha.

\section{Sosialisasi program}

Kegiatan ini bersifat pendekatan dan penyuluhan kepada perajin tentang manfaat kelanjutan program serta dampaknya terhadap tingkat produktivitas perajin.

\section{Penentuan peserta}

Peserta transfer desain adalah sebanyak 20 perajin di desa Karang Bayan, sedangkan untuk pendampingan manajemen diberikan kepada pengusaha mitra.

\section{Pelatihan transfer desain}

Pelatihan dilakukan selama 3 hari dan diikuti oleh 20 perajin. Pelatihan ini bertujuan untuk mengefektifkan proses transfer desain dari pengusaha (penerima order) ke perajin pembuat produk. Pelatihan bersifat praktis, yaitu langsung praktek membuat produk sesuai dengan desain dari pembeli (buyer)

\section{Perancangan dan pembuatan alat pengering}

Pembuatan alat pengering ini digunakan untuk mengeringkan produk anyaman ketak di musim hujan sebelum dilakukan proses pengasapan. Produk anyaman harus kering sebelum dilakukan proses pengasapan. Bila belum kering dipaksakan dilakukan proses pengasapan maka produk akan cepat diserang jamur (Marisa, 2014)

\section{Pendampingan manajemen usaha}

Pendampingan manajemen usaha dilakukan untuk memberikan motivasi dan cara-cara penyusunan pembukuan keuangan yang benar, praktis dan informatif. Sehingga model pembukuan dikemas lebih sederhana namun tanpa mengurangi esensi dan tujuan dari kegiatan pendampingan manajemen usaha ini.

\section{HASIL DAN PEMBAHASAN \\ Proses transfer desain}

Sementara ini proses transfer desain dari pengusaha ke perajin dilakukan secara door to door. Pengusaha mendatangi setiap rumah para perajin untuk memberikan desain baru dan sekaligus mendampingi proses pembuatannya. Metode seperti ini menguras waktu dan tenaga, sehingga kurang efektif. Di satu sisi waktu pesanan (order) terbatas dan pesanan harus tepat 
waktu. Satu solusi untuk yang diterapkan adalah dengan transfer desain terpusat. Metode ini bisa mengeliminir waktu dan tenaga, karena ada 20 perajin yang bisa mengikuti transfer desain dalam waktu yang bersamaan dalam satu tempat.

Proses transfer desain diperlihatkan pada Gambar 1. Kontrol pengerjaan secara langsung bisa dilakukan dan bila ada kekeliruan langsung dapat diperbaiki. Diskusi antar perajinpun berlangsung sehingga terjadi proses saling tukar kemampuan dan saling mengoreksi

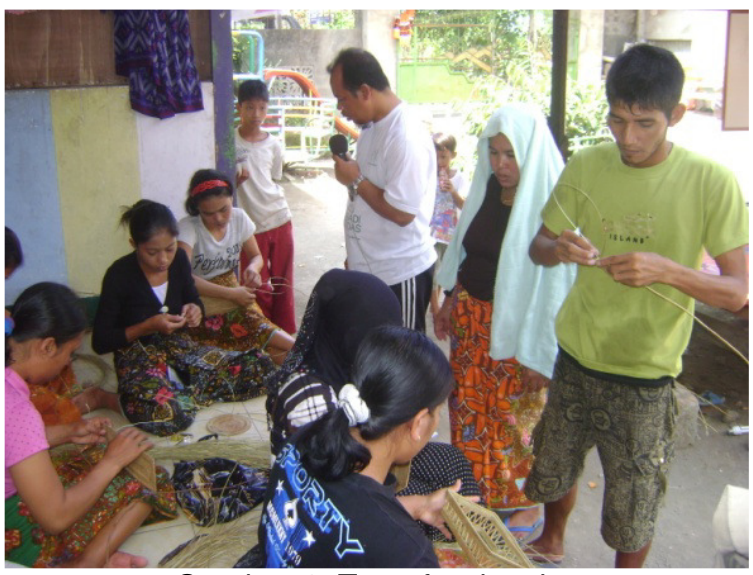

Gambar 1. Transfer desain.

Adapun materi desain yang disampaikan pada saat pelatihan transfer desain adalah desain yang diberikan oleh pemesan produk dari Jepang dan sebelumnya dikirim via email ke mitra usaha (kegiatan).

\section{Perancangan, pembuatan dan pemanfaatan alat pengering}

Alat pengering yang dirancang dan dibuat adalah alat pengering sederhana dengan sumber panasdari kompor LPG yang terletak di sisi bawah kiri dan kanan alat. Alasan penggunaan LPG adalah panas yang dihasilkan bersih, ekonomis dan mudah diperoleh serta berkelanjutan. Karena letak sumber panas disamping maka dibutuhkan fan untuk mennghembuskan udara panas ke dalam ruang pengering (Gambar 2).

Pemanfaatan dua sumber panas ditujukan untuk memperoleh kondisi pengeringan yang merata. Diperoleh sirkulasi panas yang merata di seluruh ruangan alat pengering. Di seluruh dinding bagian dalam diberi lapisan karet dan aluminium foil (isolasi) untuk mencegah kehilangan panas (heat losses), sehingga bisa tercapai efisiensi yang tinggi pada alat pengering ini.

Sumber panas memanfaatkan LP. Temperatur ruangan diatur tidak terlalu panas dan tidak dingin, diatur suplay gas pada kompor. Bila terlalu panas, konsumsi gas boros, sehingga diatur temperatur dalam ruang pengering berkisar $50^{\circ} \mathrm{C}$ [4]. Pada penggunaan temperatur ini tingkat efektivitas alat pengering paling baik.

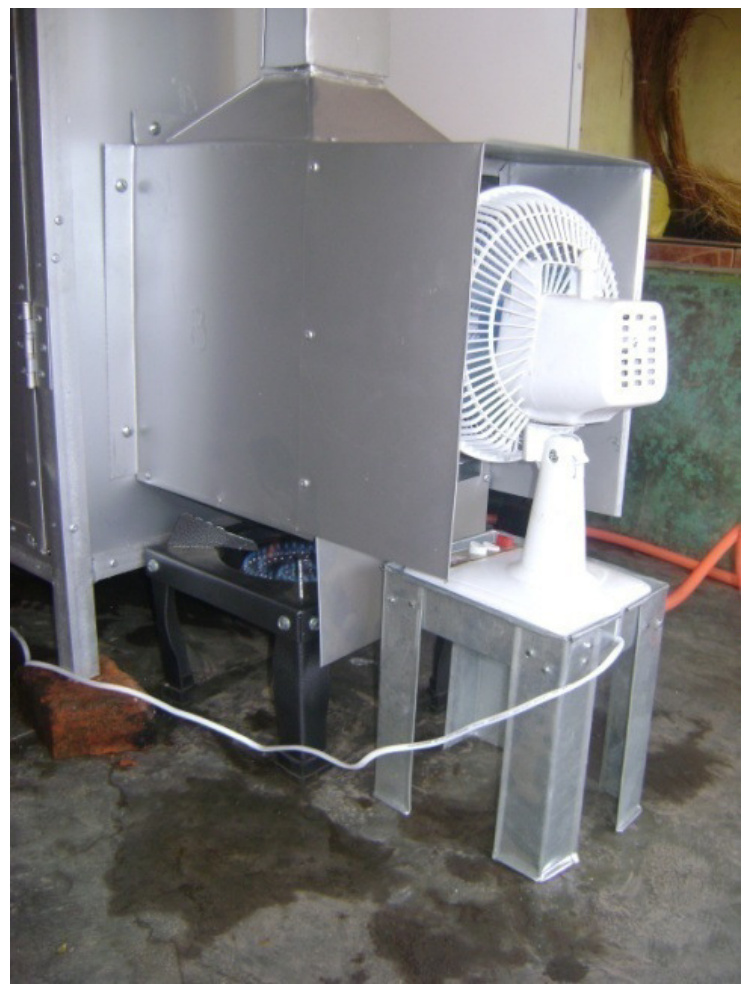

Gambar 2. Fan untuk menghembuskan udara panas.

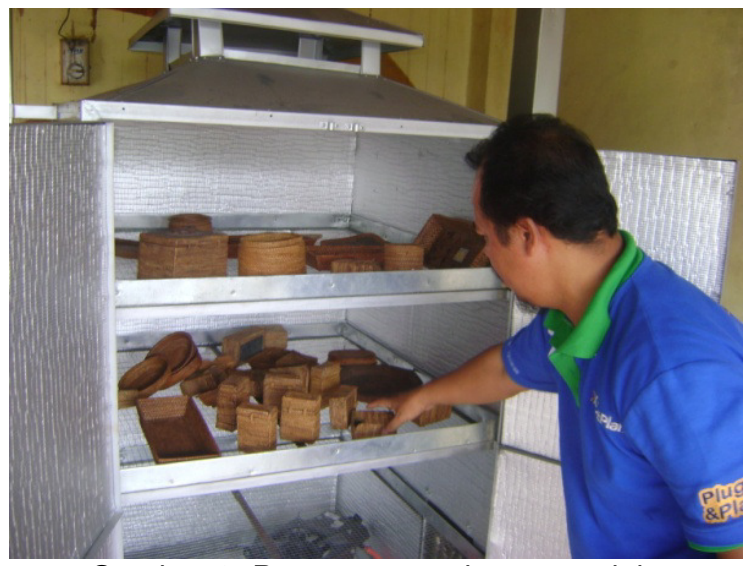

Gambar 3. Proses pengeringan produk.

Saat uji coba pengeringan, produk yang akan dikeringkan ditimbang dulu, agar diketahui selisih berat basah dan kering untuk memperoleh persentase tingkat pengeringan. Berdasarkan ketentuan tersebut dan setelah dilakukan proses pengeringan diperoleh hasil rata-rata pengurangan bobot produk berkisar 10-15\% dengan waktu 
proses pengeringan 4 jam. Kandungan air yang terkandung dalam produk akan berkurang akibat pemanasan tersebut. Bila proses pengeringan tidak maksimal maka akan bisa menyebabkan jamuran pada produk tersebut. Proses pengeringan diperlihatkan pada Gambar 3.

\section{Pendampingan manajemen usaha}

Secara umum pengeloaan usaha yang dilakukan oleh industri rumah tangga atau industri kecil masih tradisional terutamanya pengelolaan keuangan. Manajemen keuangan usaha masih bergabung dengan keuangan keluarga. Dengan kondisi seperti ini, sangat menyusahkan untuk menilai apakah usaha yang dijalankan memang menguntungkan dan keuntungannya seberapa.

Dengan kondisi tersebut, sangat tepat dilakukan metode pendampingan oleh tim yang berkompeten terkait pengelolaan usaha industri mitra. Untuk lebih memfokuskan arah pendampingan maka fokus pendampingan ditujukan pada manajemen keuangan dan manajemen pemasaran.

Manajemen keuangan usaha, tegas disini bahwa tidak boleh pembukuan keuangan keluarga dijadikan satu dengan keuangan usaha. Disini ditekankan kepada mitra usaha agar benar-benar disiplin mencatat keluar masuknya uang usaha.Pengelolaan keuangan yang baik akan mencerminkan suatu usaha dikelola dengan baik. Kegiatan pendampingan secara intensif diperlihatkan pada Gambar 4.

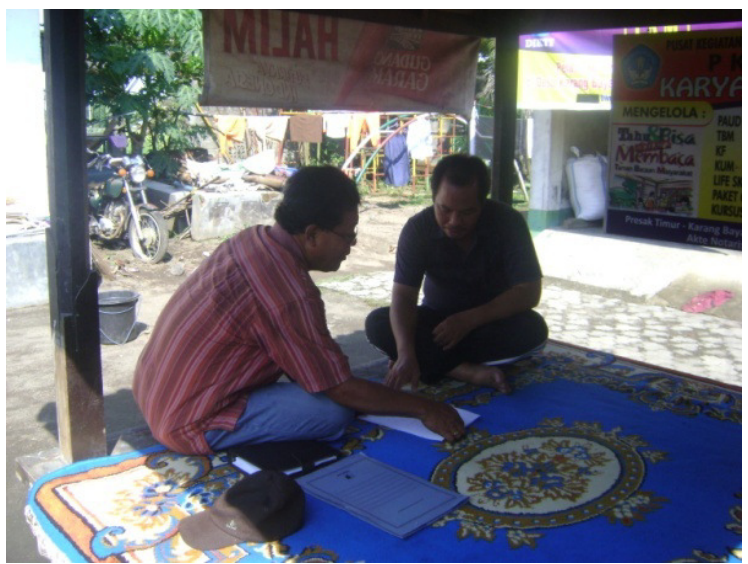

Gambar 4. Kegiatan pendampingan manajemen.

Untuk mempercepat pemahaman manajemen keuangan dan pemasaran, maka oleh tim dibuat format pembukuan yang sederhana, aplikatif dan informatif serta pemberian contoh secara langsung.

\section{KESIMPULAN}

Dari hasil pelaksanaan kegiatan program ipteks bagi masyarakat dapat ditarik beberapa kesimpulan sebagai berikut:

1. Transfer ipteks dapat berjalan dengan baik, masyarakat antusias untuk menetima ipteks yang diberikan oleh tim pelaksana dan mitra usaha sudah mampu membuat pembukuan keuangannya.

2. Pemanfaatan alat pengering sangat membantu untuk menyelesaikan pesanan saat musim hujan karena pesanan datang tidak mengenal musim.

3. Pola transfer desain terpusat sangat membantu efektivitas penyelesaian pesanan.

\section{UCAPAN TERIMA KASIH}

Selama pelaksanaan kegiatan ini penulis telah menerima banyak bantuan, masukan, dana dan fasilitas dari berbagai pihak. Oleh karena pada kesempatan ini kami menyampaikan terima kasih kepada : Kemenristek Dikti, Ketua LPM Unram, Dekan Fakultas Teknik Unram dan masyarakat perajin serta mitra kegiatan (Nusa Workshop) desa Karang Bayan Lombok Barat.

Demikian pula kepada semua pihak yang tidak dapat disebutkan satu persatu yang telah banyak membantu sehingga terselenggaranya kegiatan ini.

\section{DAFTAR PUSTAKA}

Anonim, 2014, Dinas Perindustrian dan Perdagangan Propinsi Nusa Tenggara Barat.

Agustina D., Syuhada A., 2003, Kaji eksperimental sistem pengering dengan serbuk kayu sebagai bahan bakar, Jurnal Teknologi, $3(1)$.

Efrida B., 1999, Penerapan teknologi pengeringan tepat guna pada industri kayu skala kecil, Mapeki.

Marisa F., Hidayat F., Hardianto A., 2014, IbM industri rumah tangga kerupuk mujair di desa Senggreng Kecamatan Sumber Pucung Kabupaten Malang, Jurnal Dinamika Dot Com, 7(1). 